\title{
Medidas de educação em saúde sobre infecções sexualmente adquiridas para escolares do ensino médio
}

\author{
Ruaan Oliveira Carvalho ${ }^{1}$, Willamis Tenório Ramos ${ }^{2}$, Gabrielle Novais Manzoli', \\ Magna Galvão Peixoto ${ }^{3}$, Daniela Raguer Valadão de Souza ${ }^{3}$, Deison Soares de Lima ${ }^{3}$
}

Resumo: As Infecções Sexualmente Transmissíveis (ISTs) são um problema de saúde pública mundial. No Brasil, as ISTs atingem todas as faixas etárias, em especial, os adolescentes. O objetivo do trabalho é relatar o processo de construção de uma intervenção de educação em saúde sobre IST, tendo como público alvo os escolares do ensino médio do município de Lagarto, SE. Trata-se de um estudo do tipo relato de experiência. Participaram da construção da intervenção 40 extensionistas, sendo 12 membros executores e 28 monitores dos cursos da área da saúde. Além disso, foram construídas 12 estações, abordando: HIV/AIDS, Hepatite, Sífilis, Gonorreia, HTLV-1, Herpes, Candidíase, HPV/Cancro, Vaginite Bacteriana, Sistema Reprodutor Masculino/Feminino, Comorbidades AIDS e Tricomonas. O material desenvolvido possibilitará, aos escolares, embasamento de qualidade científica que poderão norteá-los nas decisões que contemplem a temática das IST.

Palavras-chave: Infecções Sexualmente Transmissíveis. Adolescentes. Educação em Saúde.

Área Temática: Saúde.

\section{Health education measures on sexually acquired diseases for high school students}

\begin{abstract}
Sexually Transmitted Infections (STI) are a worldwide public health problem. In Brazil, STIs affect all age groups, especially adolescents. The objective of this study is to report the construction process of a health education intervention on STI, with a target audience of high school students in the city of Lagarto, SE. This is an experience report study. Forty extensionists participated in the construction of the intervention, being 12 executing members and 28 monitors from the health area courses. Additionally, 12 stations were built, approaching: HIV/AIDS, Hepatitis, Syphilis, Gonorrhea, HTLV-1, Herpes, Candidiasis, HPV/Cancer, Bacterial Vaginitis, Male/Female Reproductive System, AIDS and Trichomonas. The dissolved material will enable the students to have a scientific quality basis that can guide them in the decisions that contemplate the theme of STI.
\end{abstract}

Keywords: Sexually Transmitted Infections. Adolescents. Health Education.

\section{Medidas de educación sanitaria sobre enfermedades adquiridas sexualmente para estudiantes de la escuela secundaria}

Resumen: Las infecciones de transmisión sexual (ITS) son un problema de salud pública en todo el mundo. En Brasil, las ITS afectan a todos los grupos de edad, especialmente a los adolescentes. El objetivo de este estudio es informar sobre el proceso de construcción de una intervención de educación para la salud sobre las ITS, dirigida

\footnotetext{
${ }^{1}$ Acadêmico do Curso de Farmácia da Universidade Federal de Sergipe (UFS).

${ }^{2}$ Acadêmico do Curso de Fisioterapia da Universidade Federal de Sergipe (UFS).

${ }^{3}$ Departamento de Educação em Saúde da Universidade Federal de Sergipe (UFS)
} 
a los estudiantes de la escuela secundaria en el municipio de Lagarto, SE. Se trata de un estudio de informe de experiencia. En la construcción de la intervención participaron 40 extensionistas, siendo 12 miembros ejecutores y 28 monitores de los cursos del área de salud. Además, se construyeron 12 estaciones que abordan: VIH/SIDA, Hepatitis, Sífilis, Gonorrea, HTLV-1, Herpes, Candidiasis, VPH/Cáncer, Vaginitis bacteriana, Sistema reproductor masculino/femenino, SIDA y Tricomonas. El material disuelto permitirá a los alumnos tener una base científica de calidad que les oriente en las decisiones que contemplan el tema de las ITS.

Palabras clave: Infecciones de transmisión sexual. Adolescentes. Educación para la salud.

\section{INTRODUÇÃO}

As Infecções Sexualmente Transmissíveis (ISTs) são um problema de saúde pública mundial, sendo provocadas por mais de 30 agentes etiológicos, entre eles: vírus, bactérias, fungos e protozoários. O processo de transmissão e infecção envolve relações sexuais sem utilização de preservativos, contaminação por via sanguínea e até mesmo pela propagação durante a gestação (BRASIL, 2015).

O período da adolescência caracteriza-se por transformações fisiológicas e psicossociais, com destaque para curiosidades, experimentações e descobertas que envolvem a puberdade, a exemplo da libido. Além disso, pode ser influenciado pelo contexto socioeconômico, familiar e territorial. Por conseguinte, o início precoce das relações sexuais pode favorecer um comportamento sexual de risco, associado pela falta de informação e conscientização do ato (FELISBINO-MENDES et al., 2018; NEVES et al., 2017; SBP, 2018).

Em um estudo realizado por Farias e colaboradores (2019), em 06 escolas públicas do município de Passos - MG, observou-se que cerca de 106 adolescentes praticaram sua primeira relação sexual entre os $14 \mathrm{e}$ 16 anos. Os dados preocupam, visto que muitas vezes os adolescentes são desprovidos de conhecimento sobre o que estão sendo expostos, o que pode levar a adquirir alguma IST, ou desenvolver uma gravidez precoce (NOBRE et. al, 2020).

Em uma pesquisa com amostra de 195 adolescentes de escolas públicas do município de Caxias - MA, constatou-se que as ISTs mais conhecidas, em ordem decrescente, foram: HIV/AIDS (73,3\%), sífilis (42,1\%), gonorreia $(33,8 \%)$, verrugas genitais $(26,2 \%)$, vaginose bacteriana $(14,4 \%)$, candidíase $(12,3 \%)$, cancro mole $(10,8 \%)$, tricomoníase $(8,7 \%)$, condiloma acuminado (4,1\%) e herpes $(1,5 \%)$ (CARVALHO; PINTO; SANTOS, 2018).

Neste sentido, ações de educação em saúde sobre as ISTs são fundamentais, pois direcionam o olhar para necessidades específicas, por meio de uma escuta ativa e compreensão dos fatores biopsicossociais dos adolescentes., Aliadas às metodologias ativas, como ferramentas e medidas estratégicas eficazes no fomento de conhecimento, podem levar a uma diminuição do comportamento de risco e quebra de tabus (MONTEIRO $e t$ al., 2019).

Nesta perspectiva, Caetano, Leite e Rosa (2017), relataram, em seu trabalho com estudantes do Ensino Médio de uma escola de Piúma-ES, que a intervenção escolar promoveu a curiosidade dos discentes pelo conteúdo das ISTs, em virtude do esclarecimento das suas dúvidas. Também apontaram a solicitação de 
preservativos, e até a submissão a testes rápidos de detecção de ISTs, situações que acabaram evidenciando como tais intervenções podem contribuir para o conhecimento, pensamento crítico e autonomia nas escolhas dos jovens.

Diante dessa problemática, idealizou-se o Projeto de Extensão Contra Infecções Sexualmente Adquiridas (PrECISA), que possui como pilar a informação para escolares do Ensino Médio da rede pública sobre as principais ISTs, seus riscos à saúde, formas de contágio e prevenção, tornando-os sujeitos protagonistas e agentes multiplicadores de conhecimento. O projeto apresenta caráter interdisciplinar, tendo colaboração de extensionistas de todos os cursos do campus, tais como: Medicina, Enfermagem, Fonoaudiologia, Terapia Ocupacional, Nutrição, Odontologia, Farmácia e Fisioterapia.

\section{OBJETIVOS}

Relatar o processo de construção de uma intervenção de educação em saúde sobre Infecções Sexualmente Transmissíveis (ISTs), dentro do Projeto de Extensão Contra Infecções Sexualmente Adquiridas (PrECISA), para escolares do Ensino Médio do município de Lagarto, SE.

\section{METODOLOGIA}

Trata-se de um estudo do tipo relato de experiência sobre o processo de construção de uma intervenção educativa sobre Infecções Sexualmente Transmissíveis (IST). O Projeto de Extensão Contra Infecções Sexualmente Adquiridas (PrECISA), teve suas atividades desenvolvidas na Universidade Federal de Sergipe (UFS), Campus Lagarto no período 2019-2020, sendo vinculado ao Departamento de Educação em Saúde de Lagarto (DESL).

Foram realizadas reuniões semanais visando aproximar, de forma progressiva, os extensionistas com a temática IST e envolveram: (1) brainstorm com toda equipe executora; (2) conhecimento prévio dos extensionistas, curiosidades e experiências vividas, acerca do nível de compreensão da temática das ISTs; (3) capacitação e aperfeiçoamento teórico para aprofundamento do tema e alicerce dos extensionistas para possíveis intervenções; (4) discussão de estações educativas sobre a temática para escolas do ensino médio da rede pública do município.

Como estratégia de facilitar e direcionar a construção das estações ao conhecimento e estabelecendo vínculo com a direção da escola e os escolares do Ensino Médio da rede pública do município de Lagarto-SE, buscou-se autorização da Secretaria de Educação Municipal (SEMED) para a realização de algumas visitas por parte dos acadêmicos extensionistas às escolas do município para conversa e análise da realidade dos adolescentes, consultando o nível de conhecimento, atitudes e práticas dos mesmos perante a temática do projeto. Após visitas, realizou-se reuniões com a equipe executora do projeto para discussão das impressões e de um possível diagnóstico situacional da realidade encontrada. Bem como a construção das estações e agendamento da intervenção do projeto com esses alunos para a ação com realização nas dependências da Universidade Federal de Sergipe. 


\section{RESULTADOS E DISCUSSÃO}

A construção da intervenção contou com a participação de 40 extensionistas, sendo 12 membros executores e 28 monitores dos cursos da área da saúde. Este perfil contribuiu bastante para a execução da atividade com natureza multidisciplinar.

Acrescenta-se que foram escolhidas e construídas (12) doze estações, abordando: HIV/AIDS, Hepatite, Sífilis, Gonorréia, HTLV-1, Herpes, Candidíase, HPV/Cancro, Vaginite Bacteriana, Sistema Reprodutor Masculino/ Feminino, Comorbidades AIDS e Tricomonas.

Ressalta-se que foi padronizado um script em que todas as estações deveriam contemplar: 1Epidemiologia; 2- formas de contágios; 3- formas de transmissão; 4-medidas de prevenção; 5-complicações decorrentes das ISTs.

Atentou-se nos momentos das reuniões ao raciocínio de contextualizar toda a realidade do público alvo, desde acessibilidade da informação e ludicidade até adaptação do vocabulário para facilitação da aquisição do conhecimento.

No Quadro 1 segue o esquema pedagógico educativo que foi utilizado para fomento do conhecimento das estações.

Quadro 1: Estações construídas para o projeto/metodologia utilizada. Lagarto/SE, 2021.

\begin{tabular}{|c|c|}
\hline ESTAÇÃO & METODOLOGIA \\
\hline 1. HIV/AIDS & \multirow{11}{*}{ Slides com imagens ilustrativas, cartazes e jogos lúdicos. } \\
\hline 2. Hepatite & \\
\hline 3. Sífilis & \\
\hline 4. HTLV-1 & \\
\hline 5. Herpes & \\
\hline 6. Candidíase & \\
\hline 7. HPV/Cancro & \\
\hline 8. Vaginite Bacteriana & \\
\hline 9. Comorbidades AIDS & \\
\hline 10. Tricomonas & \\
\hline 11. Gonorréia & \\
\hline $\begin{array}{l}\text { 12. Sistema Reprodutor } \\
\text { Masculino/Feminino }\end{array}$ & $\begin{array}{l}\text { Peças anatômicas do laboratório morfofuncional, slides } \\
\text { com imagens ilustrativas, cartazes e jogos lúdicos. }\end{array}$ \\
\hline
\end{tabular}

Fonte: Próprio autor. 
Destarte, no arcabouço metodológico da intervenção, optou-se por seguir um percurso de sequência pelas estações: (1) Sistema reprodutor masculino/feminino (figura 1); (2) Gonorreia; (3) Sífilis; (4) Hepatites; (5) Vaginite Bacteriana; (6), Candidíase; (7) HTLV-1; (8) HPV/Cancro; (9) Comodidades AIDS; (10) Herpes; (11) Tricomonas; (12) HIV/AIDS na tentativa de reverberação da curiosidade e compreensão dos escolares, pois com uma base de entendimento anatômico e fisiológico seria possível favorecer a curiosidade e interesse nas próximas estações.

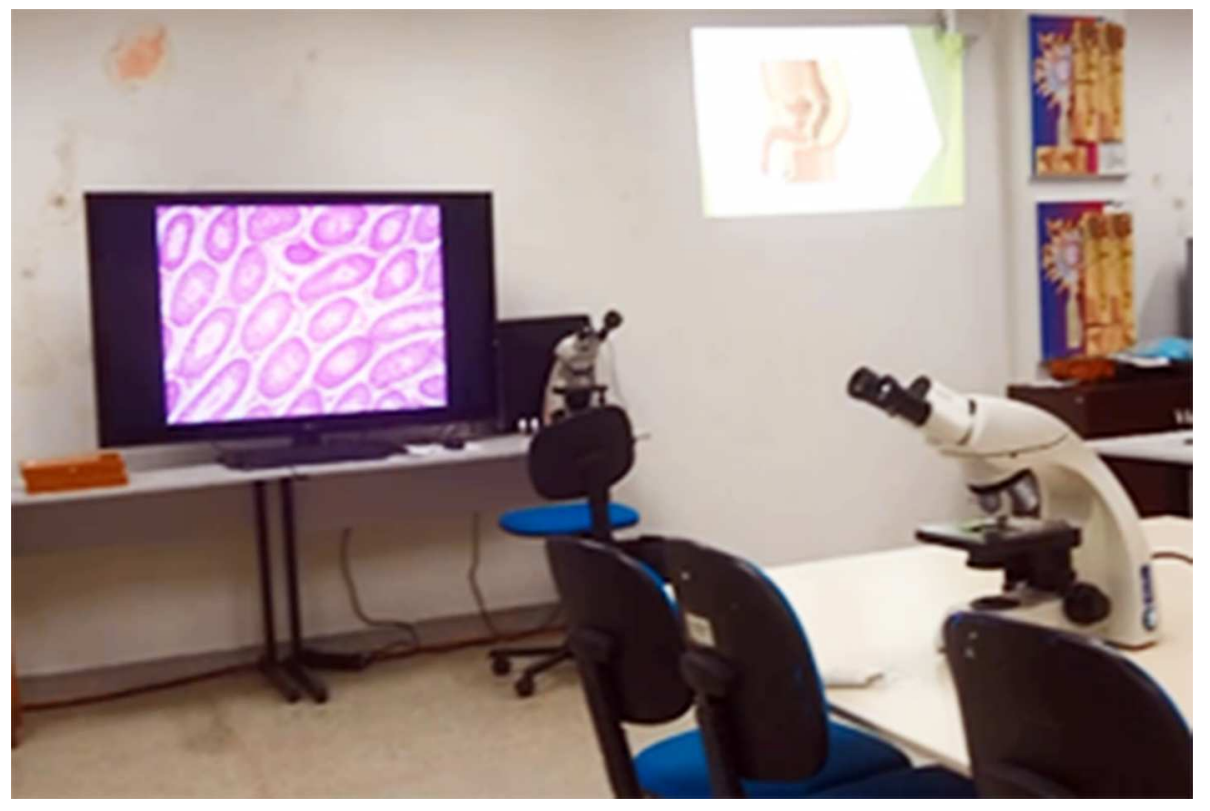

Figura 1: Estação de Sistema Reprodutor Masculino/Feminino. Lagarto/SE, 2021. Fonte: Próprio autor.

Uma intervenção realizada por meio de uma ação estratégica, utilizando a exibição da temática sobre Infecções Sexualmente Transmissíveis (ISTs) na forma de palestras, avaliou o entendimento, por meio de dois questionários, com 84 escolares de duas escolas públicas de ensino médio dentro da zona urbana do município de Cametá-PA, observou-se que 57 (67,86\%) escolares demonstraram dar importância sobre as formas de prevenção contra IST no questionário pós-intervenção (MORAIS et al., 2021).

As ações de Educação em Saúde sobre ISTs são fundamentais, pois direcionam o olhar para necessidades específicas dos escolares, por meio de uma escuta ativa e compreensão dos fatores biopsicossociais dos adolescentes, tendo as metodologias ativas como ferramentas e medidas estratégicas eficazes no fomento de conhecimento, diminuição do comportamento de risco e quebra de tabus (MONTEIRO et al., 2019).

Então, seguindo este propósito e idealizando o desenvolvimento de ferramentas metodológicas mais eficazes, o produto gerado pela intervenção foi disponibilizado para todo o público-alvo atendido pela ação, apresentando o potencial de atingir ao menos os 40 discentes envolvidos no projeto, além de todos os escolares 
da rede pública estadual do município de Lagarto. Desta forma foi possível a elaboração de 30 cartazes, 12 apresentações em powerpoint e 12 jogos lúdicos que estarão acessíveis a todas as escolas de Ensino Médio do município de Lagarto/SE e contribuirão para uma melhor discussão acerca do tema, bem como um processo mais consciente de prevenção às ISTs.

\section{CONCLUSÕES}

Através do projeto PrECISA foram construídos diversos materiais lúdicos e didáticos, como apresentações em powerpoint, cartazes, jogo lúdicos, exposição de peças anatômica com a temática das ISTs para escolares do Ensino Médio do município de Lagarto, SE. Sendo assim, o material possibilitará aos escolares um embasamento com qualidade científica, que poderá norteá-los nas decisões que contemplem o tema. Além disso, a intervenção possibilitará aproximação da sociedade com o ambiente acadêmico de nível superior e contribuição para a divulgação científica.

\section{AGRADECIMENTOS}

Agradecemos a Universidade Federal de Sergipe (UFS), Campus Professor Antônio Garcia Filho, à Pró-Reitoria de Extensão (PROEX), Secretarias de Educação Municipal/Estadual, aos bolsistas, voluntários e docentes que atuaram no projeto.

\section{FINANCIAMENTO}

O projeto foi financiado pela Pró-Reitoria de Extensão (PROEX).

\section{REFERÊNCIAS}

BRASIL. Ministério da Saúde. Departamento de Vigilância, Prevenção e Controle das IST, do HIV/AIDS e das hepatites virais. Protocolo Clínico e Diretrizes Terapêuticas para Atenção Integral às Pessoas com Infecções Sexualmente Transmissíveis. 2015.

CAETANO, Athyla; LEITE, Sidnei Quezada Meireles; ROSA, Caroline Azevedo. Educação em saúde na escola: plano de intervenção escolar para debater infecções sexualmente transmissíveis no ensino médio. Experiências em Ensino de Ciências, v. 12, n. 8, p. 227-38, 2017.

CARVALHO, Oliveira; PINTO, Raydelane Grailea Silva; SANTOS, Márcia Sousa. Conhecimento sobre as infecções sexualmente transmissíveis por estudantes adolescentes de escolas públicas. Adolescência e Saúde, v. 15, n. 1, p. 7-17, 2018.

FARIAS, Cristielle Amaro Machado et. al. Conhecendo as práticas sexuais de adolescentes alunos de escolas públicas em município de Minas Gerais. Revista Atenas Higeia, v. 1, n. 2, p. 46-53, 2019. 
FELISBINO-MENDES, Mariana Santos; PAULA, Thayane Fraga de; MACHADO, Ísis Eloah; OLIVEIRA-CAMPOS, Maryane; MALTA, Deborah Carvalho. Análise dos indicadores de saúde sexual e reprodutiva de adolescentes brasileiros, 2009, 2012 e 2015. Rev. bras. epidemiol., São Paulo, v.21, supl. 1, e180013, 2018. Disponível em: <http://www.scielo.br/scielo.php?script=sci_arttext\&pid=S1415790X2018000200415\&lng=en\&nrm=iso >. Acesso em: 11 Mar. 2021.

MONTEIRO, Raissa Silva de Melo; FEIJÃO, Alexsandra Rodrigues; BARRETO, Vanessa Pinheiro; SILVA, Bárbara Coeli Oliveira da; NECO, Klebia Karoline dos Santos; AQUINO, Alana Rodrigues Guimarães de. Ações educativas sobre prevenção de HIV/AIDS entre adolescentes em escolas. Enfermería Actual de Costa Rica, San José, n. 37, p. 206-222, Dec. 2019. Disponível em: <http://www.scielo.sa.cr/ scielo.php?script=sci_arttext\&pid=S1409-45682019000200206\&lng=en\&nrm=iso >. Acesso em: 11 Apr. 2021.

MORAIS, Luane Costa; LOBATO-JUNIOR, José Maria dos Santos; COSTA, José Francisco da Silva Costa; PANTOJA, Leonardo Carlos Rodrigues; LOBATO, Marinaldo Carvalho; MENDES, Rodinely Serrão; CHAVES-NETO, Antonio Maia de Jesus. Intervenção sobre a educação sexual em duas escolas da rede pública de ensino no município de Cametá-PA. Brazilian Journal of Development, v. 7, n. 2, p. 12363 12383, 2021.

NEVES, Rosália Garcia; WENDT, Andrea; FLORES, Thaynã Ramos; COSTA, Caroline dos Santos; COSTA, Francine dos Santos; TOVO-RODRIGUES, Luciana; NUNES, Bruno Pereira. Simultaneidade de comportamentos de risco para infecções sexualmente transmissíveis em adolescentes brasileiros, 2012. Epidemiol. Serv. Saúde, Brasília, v.26, n. 3, p. 443-454, set. 2017. Disponível em: <http://scielo.iec.gov.br/ scielo.php?script=sci_arttext\&pid=S1679-49742017000300443\&lng=pt\&nrm=iso >. Acesso em: $11 \mathrm{abr}$. 2021.

NOBRE, Carla Viviane; MACIEL, Rebeca de Souza; SOUSA, Ruth Reis de; BEZERRA, Victória Régia de Brito Souza Torres; MENDES, Igor Cordeiro. Educação em saúde sobre prevenção de infecções sexualmente transmissíveis com adolescentes. Mostra Interdisciplinar do curso de Enfermagem, v. 5, n. 1, 2020 .

SOCIEDADE BRASILEIRA DE PEDIATRIA (SBP). Infecções Sexualmente Transmissíveis na Adolescência. 2018. Disponível em: <https://www.sbp.com.br/fileadmin/user_upload/21188b-GPA_ _Infec_Sexual_Transmiss_Adolesc.pdf>.Acesso em: 12 Abr. 2021.

Submetido em: 20/04/2021. Aceito em: 05/07/2021. 